\title{
In situ ambient pressure XPS observation of surface chemistry and electronic structure of $\alpha-\mathrm{Fe}_{2} \mathrm{O}_{3}$ and $\gamma-\mathrm{Fe}_{2} \mathrm{O}_{3}$
}

\section{nanoparticles}

Dorota Flak ${ }^{\mathrm{a}, \mathrm{b}, \mathrm{c}, 1}$, Qianli Chen ${ }^{\mathrm{c}, \mathrm{d}}$, Bongjin Simon Mun ${ }^{\mathrm{e}}$, Zhi Liu ${ }^{\mathrm{f}}$, Mieczysław Rękas $^{\mathrm{b}}$, Artur Braun ${ }^{\mathrm{c}}$

${ }^{a}$ NanoBioMedical Centre, Adam Mickiewicz University in Poznań, Umultowska 85, 61-614 Poznań, Poland

${ }^{b}$ Faculty of Materials Science and Ceramics, AGH University of Science and Technology, al. Mickiewicza 30, 30-059 Kraków, Poland

${ }^{c}$ Laboratory for High Performance Ceramics, Empa. Swiss Federal Laboratories for Materials Science and Technology, CH-8600 Dübendorf, Switzerland

${ }^{d}$ University of Michigan - Shanghai Jiao Tong University Joint Institute, 800 Dong Chuan Road, Shanghai 200240, China

${ }^{e}$ Department of Physics and Photon Science, Gwangju Institute of Science and Technology, Gwangju 500-712, Republic of Korea

${ }^{f}$ Advanced Light Source, Lawrence Berkeley National Laboratory, 17 Berkeley, CA 94720, USA

\begin{abstract}
Fundamental understanding of charge transfer reaction is essential for the surface and interface engineering of transition metal oxides. In this study the chemical reactivity towards oxygen and hydrogen $(13 \mathrm{~Pa})$ under applied thermal conditions $(423-673 \mathrm{~K})$, of two polymorphic forms of $\mathrm{Fe}_{2} \mathrm{O}_{3}$ nanoparticles $\left(\gamma-\mathrm{Fe}_{2} \mathrm{O}_{3}\right.$ and $\left.\alpha-\mathrm{Fe}_{2} \mathrm{O}_{3}\right)$ are investigated with the combination of in situ ambient pressure X-ray photoelectron spectroscopy (AP-XPS) and near edge X-ray absorption fine structure spectroscopy (AP-NEXAFS). Our data show that the reactivity of these two polymorphs has a similar character based on the contribution of oxygen vacancy defect states and related material non-stoichiometry. Their exposure to hydrogen at increased temperature results in both cases in the surface reduction. However, $\gamma$ -

\footnotetext{
${ }^{1}$ Corresponding author: dorfla@amu.edu.pl

This document is the accepted version of: Flak, D., Chen, Q., Simon Mun, B., Liu, Z., Rękas, M., \& Braun, A. (2018). In situ ambient pressure XPS observation of surface chemistry and electronic structure of $\alpha-\mathrm{Fe} 2 \mathrm{O} 3$ and $\gamma-\mathrm{Fe} 2 \mathrm{O} 3$ This manuscript version is made available under the CC-BY-NC-ND 4.0 license http://creativecommons.org/licenses/by-nc-nd/4.0/
} nanoparticles. Applied Surface Science. http://doi.org/10.1016/j.apsusc.2018.06.002
\end{abstract}


$\mathrm{Fe}_{2} \mathrm{O}_{3}$ exhibits more covalent character and undergoes the reduction preferentially with a contribution of metallic $\mathrm{Fe}^{0}$ than $\mathrm{Fe}^{2+}$, in contrast to $\alpha-\mathrm{Fe}_{2} \mathrm{O}_{3}$. Further, upon introduction of oxygen at low temperature of $423 \mathrm{~K}$, rapid re-oxidation process takes place at the $\mathrm{Fe}_{2} \mathrm{O}_{3}$ nanoparticles surface. Prepared $\gamma-\mathrm{Fe}_{2} \mathrm{O}_{3}$ and $\alpha-\mathrm{Fe}_{2} \mathrm{O}_{3}$ nanostructures exhibit in general high $\mathrm{n}$ type and p-type sensor response towards hydrogen, respectively, in a wide concentrations range.

Keywords: AP-XPS, AP-NEXAFS, $\mathrm{Fe}_{2} \mathrm{O}_{3}$ polymorphs, semiconductor surface, hematite, maghemite

\section{Introduction}

It was already emphasized years ago e.g. by Schierbaum [1], that the surface and interface engineering of polycrystalline metal oxides must be based on the atomistic understanding of the charge transfer reaction at surfaces and interfaces and of the charge carrier transport and relaxation mechanism. This involves the presence of intrinsic surface defects or extrinsic metal atoms, which alter the electronic structure of metal oxides. The chemical reactivity of semiconductor metal oxides in the surrounding oxidizing and reducing atmosphere at elevated temperatures, being a consequence of modification of their surface chemical composition and resulting electronic structure is still a matter of research, though a great improvement of its applicable side.

Transition metal oxides $\left(\mathrm{MO}_{\mathrm{x}}\right)$, in spite of their seemingly simple stoichiometry, are complex systems exhibiting different bonding properties due to the contribution of d-orbitals. Moreover, they show variable oxidation states in addition to the crystal field splitting of $d$ orbitals. In turn, the non-transition metal oxides usually exhibit one preferred oxidation state, as other states might be not accessible due to higher energy required for adding or removing electrons from cations, when they are coordinated with oxygen ligands. In transition metal oxides this energy difference is rather small, hence they often exist in several stable oxides and are often prone to the defect formation in sub-stoichiometric metal oxides [2]. Defect rich surface of semiconductor metal oxides and defect formation reactions by incorporating impurities or surface oxygen removal (by the annealing in a vacuum, reducing gas atmosphere or inert ion bombardment), give a way to employ these materials in gas sensing applications [3]. Stoichiometry can be restored upon heating in air and oxygen containing atmosphere. Changes of the charge concentration upon such exposure play a key role in the sensing mechanism of resistive type sensors proposed by Morison [4]. This mechanism involves adsorption/desorption processes at sensor surfaces, interfaces and grain boundaries. Among 
point defects at surfaces, which are conjugated with surface electronic states, oxygen vacancies are crucial, as they can act as active sites for chemisorption of gas molecules, therefore affect the charge transfer and thus the electric properties. This is a necessary condition for resistive gas sensors. Thus, transport properties of semiconductors can be improved significantly, when additional energy levels corresponding to surface states associated with the material non-stoichiometry are available within the energy gap between the valence and conduction band $[5,6]$.

Iron (III) oxides, in their most thermodynamically stable polymorphic phase of hematite $\left(\alpha-\mathrm{Fe}_{2} \mathrm{O}_{3}\right)$ and metastable maghemite $\left(\gamma-\mathrm{Fe}_{2} \mathrm{O}_{3}\right)$, are intriguing semiconducting materials among other transition metal oxides, which are used i.a. in solar energy conversion devices and water splitting [7], heterogeneous catalysis including also photocatalysis [8], in fuel cells [9] and gas sensing applications [10]. They are narrow band gap semiconductors within the range of $1.8-2.2 \mathrm{eV}$ (depending on their synthesis and processing), chemically stable, exhibiting interesting magnetic and optical behavior. $\alpha-\mathrm{Fe}_{2} \mathrm{O}_{3}$ has the corundum structure (with hexagonal unit cell) constructed of iron atoms surrounded by six oxygen atoms, which are not bonded at corners of a regular octahedron. In turn, $\gamma-\mathrm{Fe}_{2} \mathrm{O}_{3}$ is iso-structural with magnetite (cubic crystal system), but with cation deficient sites. In $\gamma-\mathrm{Fe}_{2} \mathrm{O}_{3}$ crystal structure eight cations occupy tetrahedral sites and remaining are randomly distributed over the octahedral sites, vacancies are restricted to octahedral sites [11].

Iron oxides, as transition metal oxides with $d^{n}$ with $n \geq 1$, are susceptible for the oxidation and reduction, resulting in an electrical response with a large dynamic range, when exposed to the surrounding reactive gas atmosphere. Moreover, $\mathrm{Fe}_{2} \mathrm{O}_{3}$ next to $\mathrm{ReO}_{3}$ or $\mathrm{VO}_{2}$ is a particular exception to other transition metal oxides. This is due to partially filled $d$-orbitals $\left(d^{n}\right.$ for $0<n<10$ ), which according to the band gap model should exhibit metallic behavior. Other transition metal oxides do not fall into this category due to electron-electron and electronlattice interactions. Despite the complexity of the electronic structure and preferences toward reactions either with oxidizing or reducing gas molecules, transition metal oxides still remain as the best candidates for resistive type gas sensor, mostly due to their unique surface properties, and the high catalytic activity.

Properties of $\mathrm{Fe}_{2} \mathrm{O}_{3}$ that are used for aforementioned applications are related to the electronic configuration and valency of Fe. Considering the interaction of oxide with the surrounding gas atmosphere, nearly stoichiometric $\mathrm{Fe}_{2} \mathrm{O}_{3}$ is quite inert for the surface gas adsorption, probably due to the stability of the half-occupied $d$-band configuration. However, defect-rich surface provides more active sites for the interaction with gas molecules [12-15]. The defect 
structure of $\mathrm{Fe}_{2} \mathrm{O}_{3}$ is also relevant for switching their charge carrier type (n- or p-type), which can be controlled e.g. by the material doping, thermal conditions and selection of surrounding gas atmosphere [16]. This effect can have a significant impact on gas sensing properties of $\mathrm{Fe}_{2} \mathrm{O}_{3}$, in particular on their selectivity towards either reducing or oxidizing gases. From the electrical and electronic behavior point of view, n-type conductivity (usually expected and reported for hematite) is associated with the presence of free electrons established by oxygen vacancies and excess of iron sites, while p-type conductivity is due to the presence of iron vacancies and associated electron holes.

The understanding of principles of surface and/or bulk interaction with surrounding gases is expected to lead to the development of materials with an increased sensitivity, selectivity and stability, when considering e.g. gas sensing applications. Recent progress of spectroscopic tools, devoted to the assessment of physico-chemical processes taking place in the sensing material in a real time and under operating conditions, has introduced a new trend in the research on gas sensors. In situ and operando methods are important for all device-related studies, including gas sensors, since the historical "pressure gap" dilemma is now overcome with ambient pressure or close to ambient pressure X-ray photoelectron spectroscopy (APXPS) and near edge X-ray absorption fine structure spectroscopy (NEXAFS) [17, 18]. By applying spectroscopy along with the electroanalytical techniques they contribute to the deeper understanding of chemical reactivity on the molecular scale in terms of the electronic structure changes [19-21].

Therefore, in this study the ambient pressure XPS (AP-XPS) and AP-NEXAFS in situ approach towards the surface chemistry and electronic structure of two polymorphic forms of $\mathrm{Fe}_{2} \mathrm{O}_{3}$ (maghemite $\gamma-\mathrm{Fe}_{2} \mathrm{O}_{3}$ and hematite $\alpha-\mathrm{Fe}_{2} \mathrm{O}_{3}$ ) is presented. Reports on reactivity of $\mathrm{Fe}_{2} \mathrm{O}_{3}$ nanoparticles are mostly devoted to $\alpha-\mathrm{Fe}_{2} \mathrm{O}_{3}$ and focus only on the interaction with one type of gas atmosphere. In this study, the reactivity of $\mathrm{Fe}_{2} \mathrm{O}_{3}$ nanoparticles is investigated under reducing (hydrogen) and oxidizing (oxygen) gas atmosphere, also as a function of applied thermal conditions.

\section{Experimental}

$\mathrm{Fe}_{2} \mathrm{O}_{3}$ nanoparticles were prepared by the one-step flame spray synthesis (FSS) using $0.5 \mathrm{M}$ solution of ferrocene $\left(\mathrm{Fe}\left(\mathrm{C}_{5} \mathrm{H}_{5}\right)_{2}, 98 \%\right.$, Sigma-Aldrich) in benzene $\left(\mathrm{C}_{6} \mathrm{H}_{6}, 99.9 \%\right.$, SigmaAldrich). Detailed synthesis procedure and technical description of FSS set-up is given elsewhere $[22,23]$. As-synthesized maghemite $\left(\gamma-\mathrm{Fe}_{2} \mathrm{O}_{3}\right)$ nanoparticles were subjected to a thermal post-treatment at $823 \mathrm{~K}$ for 30 minutes in air (particular controlled) in order to induce the phase transformation towards hematite $\left(\alpha-\mathrm{Fe}_{2} \mathrm{O}_{3}\right)$ [22]. The specific surface area (SSA) of 
as-synthesized powders was determined from a 5-point $\mathrm{N}_{2}$ adsorption isotherm obtained from Brunauer-Emmett-Teller (BET) measurements (Beckman-Coulter SA3100). Powder X-ray diffraction (XRD) was performed with a Philips PANalytical X'Pert Pro MPD diffractometer using $\mathrm{Cu} \mathrm{Ka}$ filtered radiation over a 20range from $20^{\circ}$ to $80^{\circ}$. Powders of prepared nanoparticles were then uniaxial pressed into pellets with diameter of $10 \mathrm{~mm}$ and thickness of $2 \mathrm{~mm}$. Metallic contacts were provided by $\mathrm{Au}$ electrodes deposited by the evaporation in vacuum from crucibles heated by an electron beam, with a shape-mask. For sufficient electrical contact with electrodes, pellet sample prior to the investigation, was mounted on a sample holder with spring-loaded probe tips (Fig. 1).

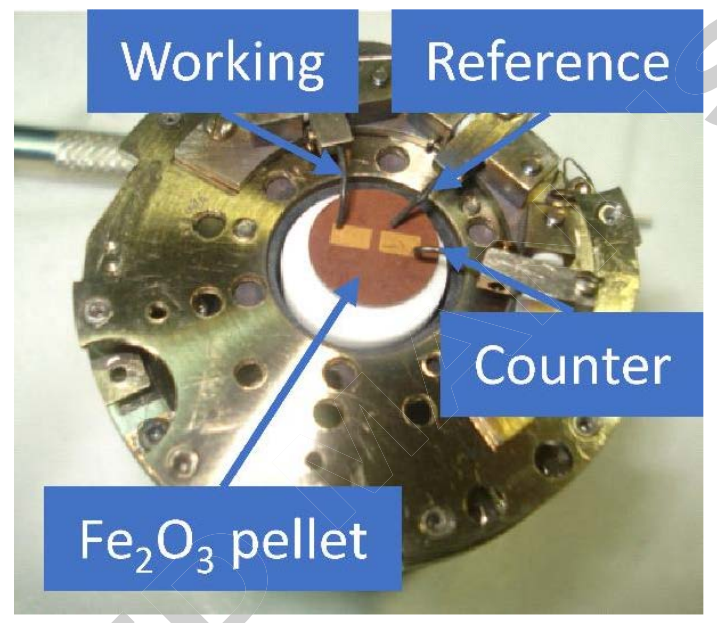

Fig. 1. Sample holder for operando / in situ XPS experiments under thermal gas phase electrochemical conditions [24-25] with the iron oxide pellet fixed to the sample holder and electric terminals.

Ambient pressure X-ray photoemission (AP-XPS) and near edge X-ray absorption fine structure spectroscopy (AP-NEXAFS) experiments were performed at beamline 9.3.2 of the Advanced Light Source at Lawrence Berkeley National Laboratory, California [26-28]. The endstation is equipped with the hemispherical Scienta 4000R-HiPP ambient pressure photoemission spectrometer (APPES) with two dimensional detector consisting of two multi channels plates coupled to a phosphor screen and charge coupled device camera (MCPs/CCS). The energy resolution of the beamline is about $\mathrm{E} / \Delta \mathrm{E}=3000$. The ambient pressure analysis chamber is separated by a series different pumping systems and apertures from the electron analyzer, which operates at ultra-high vacuum of around about $1.2 \times 10^{-6} \mathrm{~Pa}$. The measurements conditions and their sequence were as follow: $13 \mathrm{~Pa} \mathrm{O}_{2}$ exposure at $423 \mathrm{~K}$ (only for $\alpha-\mathrm{Fe}_{2} \mathrm{O}_{3}$ ), $13 \mathrm{~Pa} \mathrm{H}_{2}$ exposure at $423 \mathrm{~K}, 573 \mathrm{~K}$ and $673 \mathrm{~K}$, and $13 \mathrm{~Pa} \mathrm{O}_{2}$ exposure at $423 \mathrm{~K}, 573 \mathrm{~K}$ and $673 \mathrm{~K}$. Firstly, the sample was exposed to the gas atmosphere at ambient temperature and then the temperature was increased step-by-step. After equilibration of 
sample in the given gas and temperature, the XPS core level (O 1s, Fe 2p), valence band (VB), as well NEXAFS spectra were recorded in situ. The endstation at BL 9.3.2. has a limited number of electrical feedthroughs available for the AP-XPS measurements. It is therefore not possible to combine thermocouples for temperature measurements simultaneously. Therefore, the temperature calibration was carried out externally and actual temperature under $\mathrm{H}_{2}$ and $\mathrm{O}_{2}$ exposure may slightly deviate (approx. $10 \mathrm{~K}$ ) from the given $423-673 \mathrm{~K}$.

The XPS spectra were recorded with a PHI LS5600 spectrometer. The binding energies were calibrated by using $\mathrm{Au} 4 \mathrm{f}_{7 / 2}$ peak position at $84 \mathrm{eV}$. The Voigt, the combination of GaussianLorentzian (GL), fit function was applied for the analysis of experimental XPS results. The NEXAFS spectra were collected in total electron yield (TEY) detection mode. The overall energy resolution was set to $100 \mathrm{meV}$ at the soft X-ray energy for the oxygen $\mathrm{K}$-edge, and metal L-edge.

The morphology of particles were investigated using transmission electron microscopy (TEM). TEM images were recorded with a high-resolution and analytical HRTEM Jeol ARM $200 \mathrm{~F}$ operating at $200 \mathrm{kV}$.

The DC gas sensor measurements were carried out as well on the disc-shaped bulk nanosensors inside a closed quartz tube placed coaxially inside a resistively heated furnace, with remotely controlled temperature and gas delivery. The sensor response (S) is defined as the ratio of resistance in the presence of target gas $\mathrm{R}$ to the resistance in the reference atmosphere at constant voltage $(2 \mathrm{~V}), \mathrm{R}_{0}$, i.e. $\mathrm{S}=\left(\mathrm{R}-\mathrm{R}_{0}\right) / \mathrm{R}_{0}$.

\section{Results and discussion}

Considering the importance of the interface between the solid and gas for the mutual interactions, $\gamma-\mathrm{Fe}_{2} \mathrm{O}_{3}$ and $\alpha-\mathrm{Fe}_{2} \mathrm{O}_{3}$ nanoparticles are polycrystalline and provide high specific surface area of $95 \mathrm{~m}^{2} / \mathrm{g}\left(\mathrm{d}_{\mathrm{TEM}}=11.98 \mathrm{~nm}\right)$ and $25.3 \mathrm{~m}^{2} / \mathrm{g}($ length $\mathrm{TEM}=157 \mathrm{~nm}$, width TEM $=42$ $\mathrm{nm})$, respectively. As observed in Fig. 1 the post-treatment of $\gamma-\mathrm{Fe}_{2} \mathrm{O}_{3}$ resulted in the significant particle size increase next to the phase transformation into $\alpha-\mathrm{Fe}_{2} \mathrm{O}_{3}$, due to the sintering with the formation of prolate worm-like aggregates [22]. 

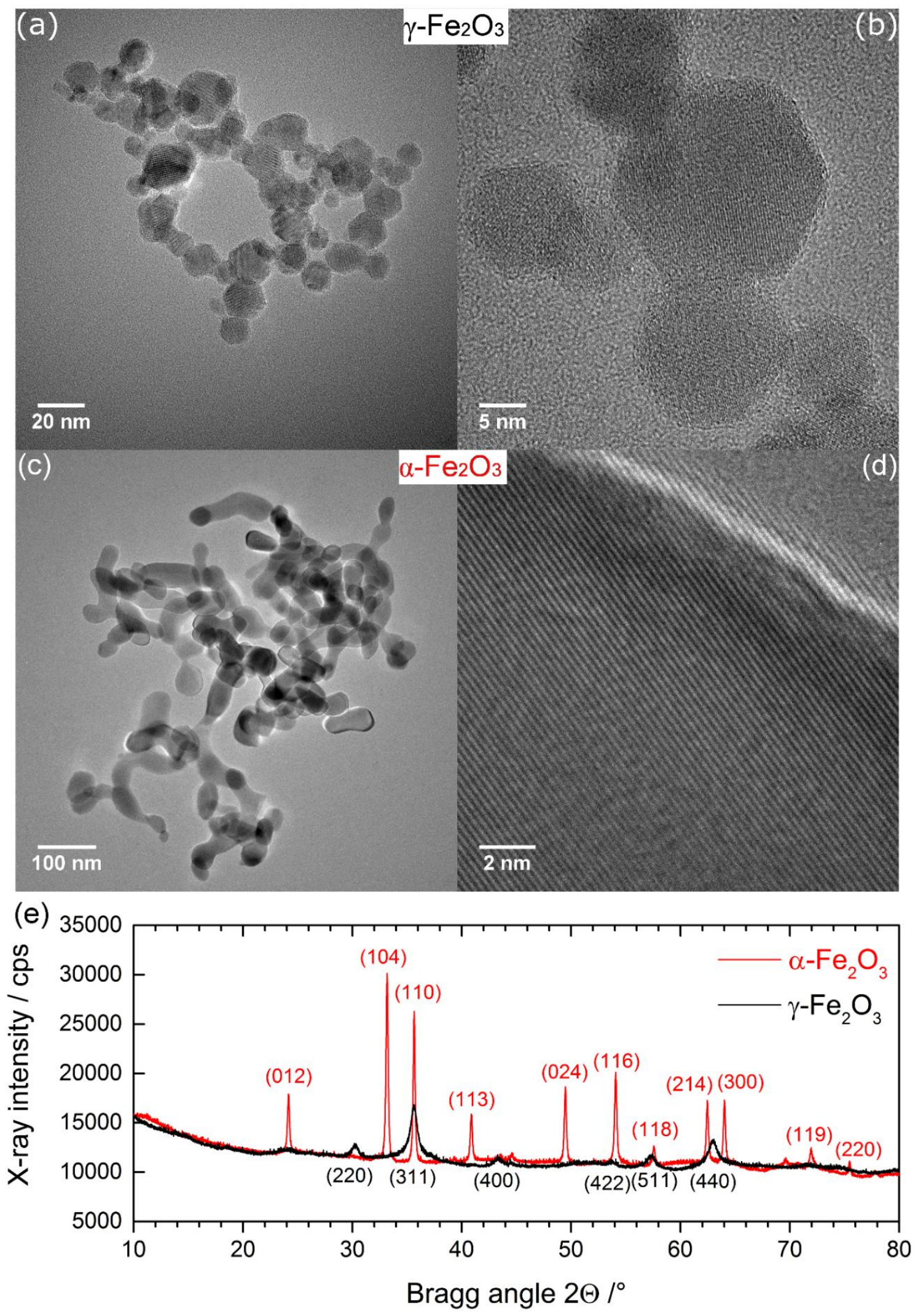

Fig. 1 (HR-)TEM images (a-d) and XRD diffractograms (e) of prepared $\mathrm{y}-\mathrm{Fe}_{2} \mathrm{O}_{3}$ (black color, broad reflections) and $\alpha-\mathrm{Fe}_{2} \mathrm{O}_{3}$ nanoparticles (red color, sharp reflections. (hkl) indices for $\mathrm{Y}$ $\mathrm{Fe}_{2} \mathrm{O}_{3}$ are noted at the bottom in black; indices for $\mathrm{aFe}_{2} \mathrm{O}_{3}$ are noted on the top of diffractogram in red. 
The X-ray diffractograms in Fig. 2 were recorded from powders. Visual inspection of the Bragg reflections reveals broader peaks (large full width at half maximum FWHM) for the maghemite and sharper peaks for the hematite. This is in line with the experience that maghemite persists only in the form of very small nanoparticles due to the thermodynamic constraints of surface energy and size [29, 30]. Indexing of the Bragg reflections confirms the phase purity of our samples as hematite and maghemite.

\subsection{AP-XPS}

The chemical interaction of $\mathrm{Fe}_{2} \mathrm{O}_{3}$ samples with oxygen and hydrogen gas molecules and resulting electronic structure changes were monitored separately under each introduced gas atmosphere and as a function of temperature.

\subsubsection{O 1s core level}

$\mathrm{O} 1 \mathrm{~s}$ core level region (Fig. 3) of $\alpha-\mathrm{Fe}_{2} \mathrm{O}_{3}$ and $\gamma-\mathrm{Fe}_{2} \mathrm{O}_{3}$ exposed to ambient atmospheric and thermal conditions comprises a multi-component structure. The predominant peak is attributed to the lattice oxygen (denoted as $O_{x}^{2-}$ ) positioned at $530.17 \mathrm{eV}$ for $\alpha-\mathrm{Fe}_{2} \mathrm{O}_{3}$ and at $530.03 \mathrm{eV}$ for $\gamma-\mathrm{Fe}_{2} \mathrm{O}_{3}$ at the initial applied conditions $\left(13 \mathrm{~Pa} \mathrm{O}_{2}, 423 \mathrm{~K}\right)$ and remains at this position under the subsequent hydrogen exposure and applied temperature $\left(13 \mathrm{~Pa} \mathrm{H}_{2}\right.$ at 423 , 573 and $673 \mathrm{~K})$. During exposure to oxygen atmosphere $\left(13 \mathrm{~Pa} \mathrm{O}_{2}\right.$ at 423,573 and $\left.673 \mathrm{~K}\right)$ the main peak shifts of about $0.3 \mathrm{eV}$ and $0.5 \mathrm{eV}$ towards lower binding energy for $\alpha-\mathrm{Fe}_{2} \mathrm{O}_{3}$ and $\gamma$ $\mathrm{Fe}_{2} \mathrm{O}_{3}$, respectively and remains in this position within the entire controlled temperature range. The changes of spectra upon applied ambient conditions are also observed for peaks positioned at the higher binding energy side of the main peak.

Under initial conditions $\left(13 \mathrm{~Pa} \mathrm{O}_{2}, 423 \mathrm{~K}\right)$ three higher binding energy side peaks create characteristic tailing and are positioned at about $531.9 \mathrm{eV}$ (significant contribution), $532.9 \mathrm{eV}$ and $533.9 \mathrm{eV}$ (less significant contribution) in case of $\alpha-\mathrm{Fe}_{2} \mathrm{O}_{3}$. These peaks originate from the non-stoichiometry related hydroxyl groups $\left(\mathrm{OH}^{-}\right)$, oxygen ion species $\left(\mathrm{O}_{2}^{2-} / \mathrm{O}^{-}\right)$and the lowest from adsorbed water molecules $\left(\mathrm{H}_{2} \mathrm{O}_{a d s}\right)$, respectively [31-34]. After the hydrogen atmosphere introduction $\left(13 \mathrm{~Pa} \mathrm{H}_{2}\right)$ the last contribution of $\mathrm{H}_{2} \mathrm{O}_{\text {ads }}$ disappears, while the contribution of remaining peaks varies only slightly. Upon further heating in the hydrogen atmosphere the tailing disappearance in favor of the increasing contribution of the main peak originating from the lattice oxygen is observed. Moreover, the $0.4 \mathrm{eV}$ shift of the second peak originating from hydroxyl groups towards lower binding energy is additionally observed. Similar shift of hydroxyl group was observed in $\mathrm{BaCeY}$-oxide proton conductor exposed to 
water vapor at $532 \mathrm{~K}[35]$. These observations indicate that the chemical environment of the oxygen is more negatively charged. Upon interaction of oxide with introduced $\mathrm{H}_{2}$ gas molecules, lattice oxygen is removed from anion surface sites leaving behind defects, such as oxygen vacancies and related free electrons, which can be injected to the conduction band of an oxide.

Upon the subsequently introduced oxygen atmosphere and thermal conditions $\left(13 \mathrm{~Pa}_{2}\right.$ at 423,573 and $673 \mathrm{~K}$ ) the contribution of the lattice oxygen becomes predominant, and related peak shifts of $0.3 \mathrm{eV}$ towards lower binding energy and its intensity increases upon temperature increase. This is due to the refilling surface oxygen vacancies previously induced by $\mathrm{H}_{2}$ and bonding with $\mathrm{Fe}$ atoms at the surface. In addition, a less significant contribution of the second component $\mathrm{OH}^{-}$(at the level of around $1.5 \%$ ), as well as a double peak at around 538 - $540 \mathrm{eV}$ appears, corresponding to the oxygen gas phase, is observed.

The $\mathrm{O} 1 \mathrm{~s}$ core level region of $\gamma-\mathrm{Fe}_{2} \mathrm{O}_{3}$ under initial conditions $\left(13 \mathrm{~Pa} \mathrm{H}_{2}\right.$ at $\left.423 \mathrm{~K}\right)$ is composed of three components: $\mathrm{O}_{x}^{2-}, \mathrm{OH}^{-}$and $\mathrm{O}_{2}^{2-} / \mathrm{O}^{-}$. However, the contribution of $\mathrm{O}_{x}^{2-}$ is more predominant and the overall spectral intensity is much higher than in case of $\alpha-\mathrm{Fe}_{2} \mathrm{O}_{3}$ (see the different ordinate scale range in Fig. 2). Upon subsequent temperature increase a decreasing contribution of the higher energy side component is observed along with a decreasing overall spectral weight. Similarly, as in case of $\alpha-\mathrm{Fe}_{2} \mathrm{O}_{3}$, the $\mathrm{OH}^{-}$component is shifted towards the lower binding energy of $0.3 \mathrm{eV}$. Upon the following oxygen introduction $\left(13 \mathrm{~Pa} \mathrm{O}_{2}\right.$ ) the overall spectral weight increases, particularly the one of the lattice oxygen component, until it reaches the maximum at the final oxygen exposure at $673 \mathrm{~K}$, which is accompanied by the disappearance of other components.

The precise assignment of the lower binding energy peaks originating from $\mathrm{OH}^{-}$and $\mathrm{O}_{2}^{2-} / \mathrm{O}^{-}$ is usually difficult in relation to the existence of ionizations associated with weakly adsorbed species, which might additionally differ upon introduced gas atmospheres and thermal conditions. These peaks are associated with the non-stoichiometry of the semiconductor material, as these species can easily adsorb onto active sites available on its surface, resultant of surface defects. These non-stoichiometry-related species are strongly involved in the interaction with introduced gas molecules, as their contribution significantly decreases upon subsequently introduced gas molecules and increasing temperature.

At the first glance at the summary of the $\mathrm{O} 1$ s core level presented in Fig. 3 it is possible to make out significant differences of the spectral shape and weight for these two $\mathrm{Fe}_{2} \mathrm{O}_{3}$ polymorphs. This suggests that the their covalent character can be changed upon exposure to the certain gas atmosphere and applied temperature. The shift of the main peak towards lower 
binding energy of 0.3 and $0.5 \mathrm{eV}$ for $\alpha-\mathrm{Fe}_{2} \mathrm{O}_{3}$ and $\gamma-\mathrm{Fe}_{2} \mathrm{O}_{3}$, respectively, indicates that upon hydrogen atmosphere at $673 \mathrm{~K}$ more negative charge is expected on oxygen atoms, as the binding energy determined by the XPS for the core electrons of an atom is dependent on the chemical state of this atom. Moreover, the lower overall intensity of the $\mathrm{O} 1 \mathrm{~s}$ core level spectra upon hydrogen than upon oxygen exposure, results from the lower ion coverage. This is particularly the case of $\alpha-\mathrm{Fe}_{2} \mathrm{O}_{3}$ exhibiting lower SSA. In turn, the disappearance of the $\mathrm{O}$ 1s core level tailing in favor of an increased lattice oxygen contribution upon increasing temperature can be related to desorption of oxygen ion species and filling of the oxygen vacancies. These observations are in great accordance with the proposed gas sensing mechanisms in case of $\mathrm{MO}_{\mathrm{x}}$ semiconductors [4].

\subsubsection{Fe $2 \mathrm{p}$ core level}

Fe $2 p$ spectra of $\alpha-\mathrm{Fe}_{2} \mathrm{O}_{3}$ and $\gamma-\mathrm{Fe}_{2} \mathrm{O}_{3}$ recorded under ambient atmospheric and thermal conditions are presented in Fig. 4. These spectra have been reported to be identical for both polymorphs, despite differences in their crystal structure under UHV conditions [36, 37]. These spectra have the characteristic doublet of $\mathrm{Fe} 2 \mathrm{p}_{1 / 2}$ and $\mathrm{Fe} 2 \mathrm{p}_{3 / 2}$ at binding energies of around $725 \mathrm{eV}$ and $711 \mathrm{eV}$, respectively. The Fe $2 \mathrm{p}$ main peaks are accompanied by satellite structures characteristic for $\mathrm{Fe}^{3+}$ on their higher binding energy side (8-9 eV away). This is the case of $\mathrm{Fe}_{2} \mathrm{O}_{3}$ nanoparticles at initial measurement conditions $\left(13 \mathrm{~Pa} \mathrm{O}_{2}\right.$ and $13 \mathrm{~Pa} \mathrm{H}_{2}$ at $423 \mathrm{~K})$. According to the GL fit the contribution of both $\mathrm{Fe}^{3+}$ and $\mathrm{Fe}^{2+}$ is observed. The spectra of nanoparticles exposed to hydrogen at increased temperature $\left(13 \mathrm{~Pa} \mathrm{H}_{2}, 573\right.$ and 673 $\mathrm{K}$ ) indicate that $\mathrm{Fe}_{2} \mathrm{O}_{3}$ nanoparticles were partially reduced, as signified by the broadening of the core level $\mathrm{Fe} 2 \mathrm{p}_{3 / 2}$ peak due to formation of reduced species of $\mathrm{Fe}$, i.e. $\mathrm{Fe}^{2+}$, as well as metallic $\mathrm{Fe}^{0}$, at lower binding energy side. In addition, instead of a characteristic $\mathrm{Fe}^{3+}$ satellite peak, $\mathrm{Fe}^{2+}$ satellite peak is observed on the higher binding energy side. Finally, the chemical shift of Fe $2 p$ main peaks is observed due to the contribution of reduced Fe species.

$\gamma-\mathrm{Fe}_{2} \mathrm{O}_{3}$ nanoparticles appear more prone to the reduction, as evidenced by the significant drop of the spectra intensity and contribution enly of reduced Fe species including metallic $\mathrm{Fe}^{0}$, which is not the case of $\alpha-\mathrm{Fe}_{2} \mathrm{O}_{3}$ nanoparticles. Moreover, the higher intensity of the spectra in case of $\gamma-\mathrm{Fe}_{2} \mathrm{O}_{3}$ than $\alpha-\mathrm{Fe}_{2} \mathrm{O}_{3}$ nanoparticles, under initial conditions $\left(13 \mathrm{~Pa} \mathrm{O}_{2}\right.$ for $\alpha-\mathrm{Fe}_{2} \mathrm{O}_{3}$ and $13 \mathrm{~Pa} \mathrm{H}_{2}$ for $\gamma-\mathrm{Fe}_{2} \mathrm{O}_{3}$ at $423 \mathrm{~K}$ ) is related to the higher ion coverage of $\gamma-\mathrm{Fe}_{2} \mathrm{O}_{3}$ nanoparticles due to their higher SSA and available cation deficient sites, as compared to $\alpha$ $\mathrm{Fe}_{2} \mathrm{O}_{3}$. Higher SSA offers more chemically active sites for the interaction with surrounding gas molecules, while the oxygen deficiency, reflected in the $\mathrm{O} 1 \mathrm{~s}$ core level spectra, is preferred for gas adsorption and/or water dissociation. These results are similar to those given 
by Graat and Somers [38] on thin iron-oxide films. Also Deng et al. [31] reported on $\alpha-\mathrm{Fe}_{2} \mathrm{O}_{3}$ nanoparticle-based thin films, which were stable up to $700 \mathrm{~K}$ at UHV conditions, while the reduction took place during further heating up to $750 \mathrm{~K}$ under $\mathrm{CO}$ exposure, however no metallic $\mathrm{Fe}^{0}$ was found. In turn, de Smit et al.[39] reported on the fast reduction of bulk $\alpha-$ $\mathrm{Fe}_{2} \mathrm{O}_{3}\left(\mathrm{SSA} \sim 17 \mathrm{~m}^{2} / \mathrm{g}\right)$ to metallic $\mathrm{Fe}^{0}$, in contrast to the slow reduction in case of $\alpha-\mathrm{Fe}_{2} \mathrm{O}_{3}$ (SSA $\sim 135 \mathrm{~m}^{2} / \mathrm{g}$ ), which possess oxide-rich surface, after treatment in hydrogen. Nonstoichiometry in nanoparticulated $\mathrm{Fe}_{2} \mathrm{O}_{3}$ was also observed by Bora et al.[40], who found the $\mathrm{Fe}^{3+}$ octahedral to $\mathrm{Fe}^{2+}$ tetrahedral transition upon increasing temperature $(523-1173 \mathrm{~K})$ in ambient air. Our observations are in good accordance with results in mentioned above reports. Finally, upon subsequently introduced oxygen atmosphere $\left(13 \mathrm{~Pa} \mathrm{O}_{2}\right)$ under similar to previous thermal conditions ( 423 - $673 \mathrm{~K}$ ) significant changes of the Fe 2 p core level can be observed in case of both polymorphs. Drastic narrowing of the Fe $2 \mathrm{p}_{3 / 2}$ peak takes place along with the emerging $\mathrm{Fe}^{3+}$ satellite structure on the higher binding energy side. The GL fit reveals contribution of two $\mathrm{Fe}$ species with different ratios, predominating $\mathrm{Fe}^{3+}$ and $\mathrm{Fe}^{2+}$. This observation indicates that the reduction of these nanoparticles is a reversible process, as the $\mathrm{Fe}$ species are concerned. 


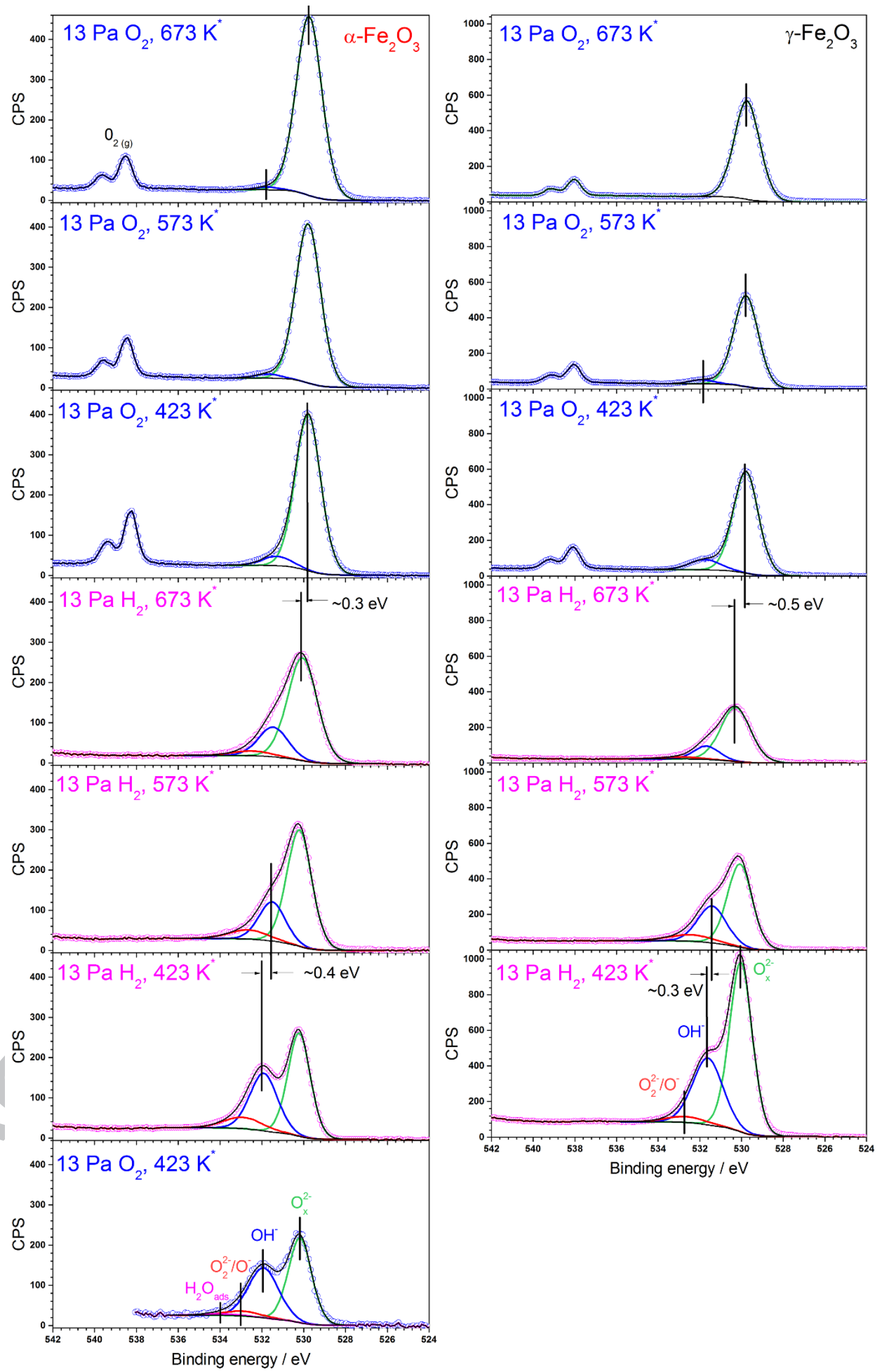

Fig. 3 Experimental (open circles) O 1s AP-XPS spectra of $\alpha-\mathrm{Fe}_{2} \mathrm{O}_{3}$ (left) and $\gamma-\mathrm{Fe}_{2} \mathrm{O}_{3}$ (right) under applied gas atmosphere and thermal conditions (see description insets in the figure). The chronological changes of introduced gas atmosphere and thermal conditions should be followed from lower to upper panel. The solid line is the least square fit with Gaussian-Lorentzian peak profile. 


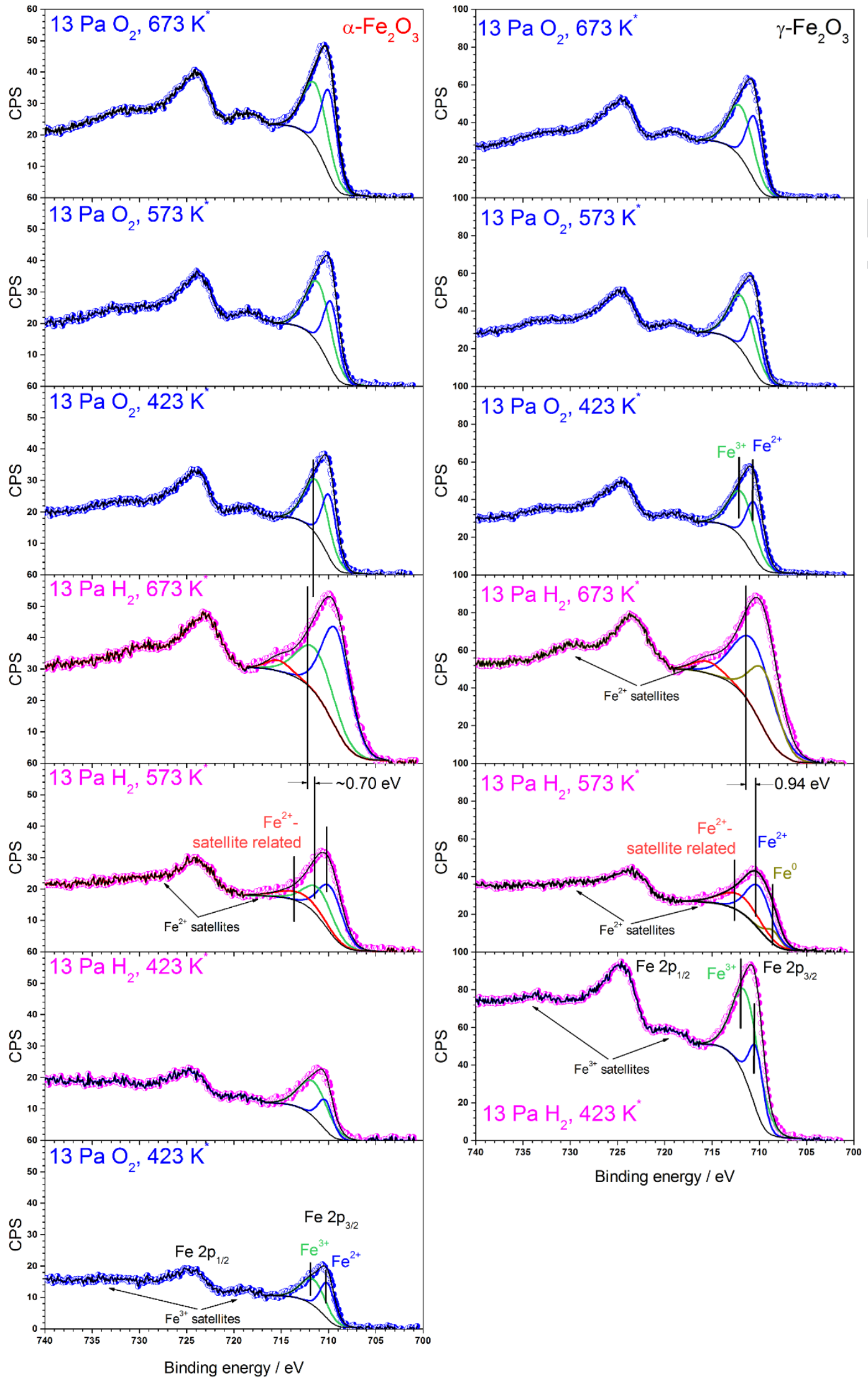

Fig. 4 Experimental (open circles) $\mathrm{Fe} 2 \mathrm{p}$ AP-XPS spectra of $\alpha-\mathrm{Fe}_{2} \mathrm{O}_{3}$ (left) and $\gamma-\mathrm{Fe}_{2} \mathrm{O}_{3}$ (right) under applied gas atmosphere and thermal conditions (see description insets in the figure). The chronological changes of introduced gas atmosphere and thermal conditions should be followed from lower to upper panel. The solid line is the least square fit with Gaussian-Lorentzian peak profile. 


\subsubsection{Valence band region analysis}

The XPS valence band region (VB) of $\alpha-\mathrm{Fe}_{2} \mathrm{O}_{3}$ and $\gamma-\mathrm{Fe}_{2} \mathrm{O}_{3}$ (Fig. 5) also reveals a relevant changes occurring upon the introduced gas atmosphere and applied temperature. These VB spectra are resultant of the hybridization between $\mathrm{Fe}(3 \mathrm{~d})$ and $\mathrm{O}(2 \mathrm{p})$ atomic orbitals and consist of a main band within the binding energy range of $0-10 \mathrm{eV}$. The main band seems to have in general a three-peak structure in the outer valence band, which is consistent with the previously reported results $[36,41,42]$. This three-peak structure is well explained by the cluster calculations reported elsewhere [37, 42]. The most intense feature corresponds to the $2 \mathrm{t}_{2 \mathrm{~g}}$ (spin up) transition, with low binding energy peaks corresponding to the $2 \mathrm{t}_{2 \mathrm{~g}}$ ( (spin up) transition and the $3 \mathrm{e}_{\mathrm{g}}$ (spin up) transition as the second peak. The third peak located at around 6-7 eV corresponds to the $2 \mathrm{e}_{\mathrm{g}}$ transition [43].

The particular attention should be devoted here to the presence of $3 \mathrm{e}_{\mathrm{g}}$ transitions near the Fermi level energy. These are particularly remarkable for nanoparticles under the hydrogen exposure in particular at $673 \mathrm{~K}$ and can be considered as a contribution of the nonstoichiometry due to the oxygen deficiency. This is in agreement with findings of Lee and Han [7], who determined the oxygen deficiency in $\alpha-\mathrm{Fe}_{2} \mathrm{O}_{3}$ under high temperature conditions with the ab initio method. Upon the comparison of these two polymorphs such contribution is more pronounced for $\gamma-\mathrm{Fe}_{2} \mathrm{O}_{3}$, as it also appears under oxygen atmosphere exposure at $573 \mathrm{~K}$ and $673 \mathrm{~K}$, however not at the initial temperature of $423 \mathrm{~K}$. This may indicate reorganizations of the oxygen non-stoichiometry between bulk and surface of those nanoparticles. The intensity of the spectra significantly decreases upon subsequent oxygen introduction and remains similar upon following applied temperatures $(423-673 \mathrm{~K})$. This is related to the difference in the number of valence states. Therefore, nanoparticles exposed to the reducing atmosphere (hydrogen) exhibit more covalent character. The comparison of spectra of both polymorphs reveals in turn a higher spectral intensity in case of $\gamma-\mathrm{Fe}_{2} \mathrm{O}_{3}$ nanoparticles (similarly for core levels), what also suggests that $\gamma-\mathrm{Fe}_{2} \mathrm{O}_{3}$ nanoparticles have more covalent character than $\alpha-\mathrm{Fe}_{2} \mathrm{O}_{3}$, in particular upon interaction with hydrogen. This indicates simply stronger hybridization between $\mathrm{Fe}(3 \mathrm{~d})$ and $\mathrm{O}(2 \mathrm{p})$ states (Fe $-\mathrm{O}$ bond electrons move towards Fe (3d) derived states) [36]. These results are in agreement with changes observed in case of $\mathrm{O} 1 \mathrm{~s}$ and $\mathrm{Fe} 2 \mathrm{p}$ core levels.

In summary, a distinct reactivity of two $\mathrm{Fe}_{2} \mathrm{O}_{3}$ polymorphs with hydrogen and oxygen gas atmospheres at various temperatures was found with the in situ XPS, in terms of their electronic structure changes. The interaction of $\mathrm{Fe}_{2} \mathrm{O}_{3}$ nanoparticles surface with oxidizing and reducing gas molecules can be considered in general as a catalytical reaction (reduction or 
oxidation at the $\mathrm{MO}_{\mathrm{x}}$ surface), giving a rise to a significant changes in the free electron concentration, which finally results in changes in the electrical behavior. In our previous publication we showed that the conductivity of this material is of electronic origin, Arrhenius activated and strongly affected by the interaction with hydrogen. Considering gas sensing purposes, $\alpha-\mathrm{Fe}_{2} \mathrm{O}_{3}$ exhibits larger relative conductivity changes as a function of temperature upon exposure to the air and hydrogen atmosphere [22]. The final reactivity of these two polymorphs seems to have in general similar character. However, the way they undergo resolves relevant differences. A significant contribution of the oxygen vacancy defect states and related material non-stoichiometry was revealed with the $\mathrm{O} 1 \mathrm{~s}$ and confirmed with $\mathrm{Fe} 2 \mathrm{p}$ core level analysis. Moreover, it was evidenced here that $\gamma-\mathrm{Fe}_{2} \mathrm{O}_{3}$ undergoes the reduction preferentially with a contribution of metallic $\mathrm{Fe}^{0}$ unlike $\alpha-\mathrm{Fe}_{2} \mathrm{O}_{3}$. This process seems to be almost entirely reversible within the processing parameter range applied here. Higher intensity of VB region of reduced samples particularly in case of $\gamma-\mathrm{Fe}_{2} \mathrm{O}_{3}$ and redistribution of the spectral weight from lower to higher binding energy upon hydrogen exposure (transitions near the Fermi level) can be interpreted with the significant changes of the $\mathrm{Fe}-\mathrm{O}$ bonding in the defect vicinity. This is related to the difference in the number of the valence states and suggests more covalent character of $\gamma-\mathrm{Fe}_{2} \mathrm{O}_{3}$ nanoparticles. These in turn indicate the higher concentration of charge carriers within the band gap, which are available for the transfer to the conduction band, that play a crucial role in a sensing of materials for resistive gas sensors.
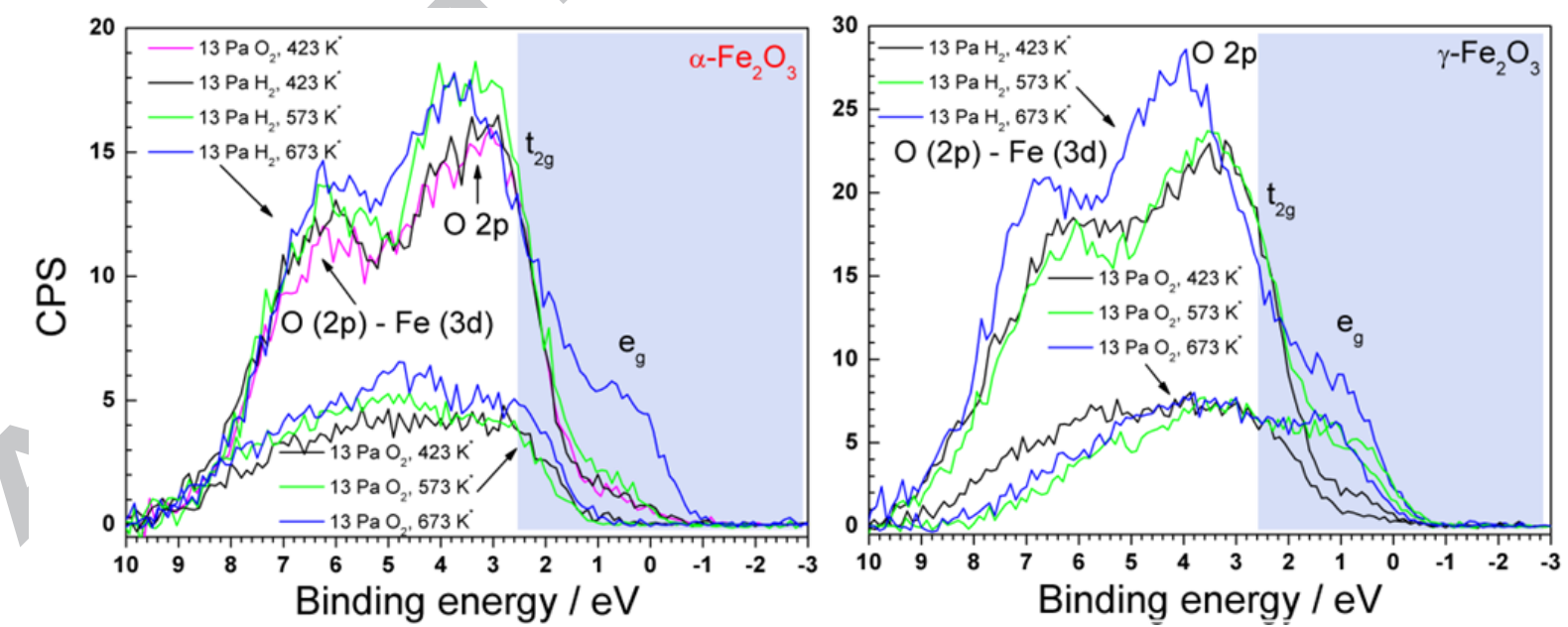

Fig. 5 XPS valence band spectra VB of $\alpha-\mathrm{Fe}_{2} \mathrm{O}_{3}$ (left) and $\gamma-\mathrm{Fe}_{2} \mathrm{O}_{3}$ (right) under applied gas atmosphere and thermal conditions (see description insets in the figure).

\subsection{NEXAFS}

The electronic structure of two $\mathrm{Fe}_{2} \mathrm{O}_{3}$ polymorphs was simultaneously probed with the ambient pressure NEXAFS spectroscopy. Normalized O K-edge spectra of $\alpha-\mathrm{Fe}_{2} \mathrm{O}_{3}$ and $\gamma$ $\mathrm{Fe}_{2} \mathrm{O}_{3}$ under hydrogen atmosphere are depicted in Fig. 6. The pre-edge region with the low 
energy transition from the atomic-like $1 \mathrm{~s}$ state to unoccupied $\mathrm{O}(2 \mathrm{p})$ orbital hybridized with Fe (3d) orbital of transition metal atom at $530 \mathrm{eV}$ shows the well-known double peak character. The splitting into $t_{2 g}$ and $e_{g}$ orbital symmetry states originates from the crystal field splitting according to the ligand-field theory. Peaks at higher energy correspond to $O(2 p)$ state hybridized with $4 \mathrm{~s}, 4 \mathrm{p}$ states of transition metal oxides, originating from scattering resonance effects.

The pre-edge region at around $530 \mathrm{eV}$ shows the well-known double peak character, indicating after one-electron transition model [44] the presence of $\mathrm{Fe}^{3+}$ ion states. Such double peak character of the pre-edge region is more pronounced in case of $\alpha-\mathrm{Fe}_{2} \mathrm{O}_{3}$, particularly at idealistic UHV conditions or at the initial temperature of $423 \mathrm{~K} . \gamma-\mathrm{Fe}_{2} \mathrm{O}_{3}$ exhibits less developed double peak character of the pre-edge region suggesting the contribution of the reduced $\mathrm{Fe}^{2+}$ next to $\mathrm{Fe}^{3+}$, what is confirmed by the comparison of experimental spectra with the reported one in the literature for $\mathrm{FeO}$ and $\mathrm{Fe}_{3} \mathrm{O}_{4}[40,44,45]$. This is also in agreement with presented above AP-XPS results. The comparison of these spectra with previously reported spectra from similar samples measured upon idealistic UHV conditions [10], as well as with those reported by Gajda-Schrantz et al. [46] for hematite samples given to the heattreatment $\left(250-1000{ }^{\circ} \mathrm{C}\right)$ in air atmosphere, or by Bora et al. [40] for temperature induced non-stoichiometric $\mathrm{Fe}_{2} \mathrm{O}_{3}$, reveal significant dissimilarities. This proves that the applied ambient atmosphere and thermal condition significantly affects the electronic structure of $\alpha$ $\mathrm{Fe}_{2} \mathrm{O}_{3}$.

Upon further exposure toward the hydrogen gas molecules and increasing temperature this peak splitting character significantly diminishes, as a strong overlap of these two peaks in preedge region is observed. $\mathrm{O}(2 \mathrm{p})$ - Fe $(3 \mathrm{~d})$ hybridization seems to be associated with a distortion, particularly in case of $\gamma-\mathrm{Fe}_{2} \mathrm{O}_{3}$. Upon further hydrogen exposure at $673 \mathrm{~K}$ the oxygen signal cannot be anymore well distinguished (insets in Fig. 6). Along with distorted hybridization a new feature at around $534 \mathrm{eV}$ is emerging. This might be assigned to the presence of the molecular oxygen, due to its release upon heating and due to the low rate of the interaction with hydrogen molecules [44]. Moreover, the broadening and shifting towards lower photon energy of the region resultant of the hybridization of transition metal atoms $\mathrm{Fe}$ $(4 s, 4 p)$ with $\mathrm{O}(2 \mathrm{p})$ state is observed. These observations are indicative of the reduction of the oxide surface upon exposure toward hydrogen under applied thermal conditions as the number of d electrons clearly increases.

Normalized Fe L-edge NEXAFS spectra of $\alpha-\mathrm{Fe}_{2} \mathrm{O}_{3}$ and $\gamma-\mathrm{Fe}_{2} \mathrm{O}_{3}$ exposed to the hydrogen and oxygen atmosphere at applied temperatures are presented in Fig. 7. In case of $\alpha-\mathrm{Fe}_{2} \mathrm{O}_{3} \mathrm{Fe} \mathrm{L}-$ 
edge spectra were firstly measured under the oxygen atmosphere at $423 \mathrm{~K}$ and followed by measurements under the hydrogen atmosphere and oxygen at increased temperatures in order to observe the impact of the order of the gas introduction. The distinct splitting, particularly at $\mathrm{L}_{3}$-edge, with the small intensity pre-peak followed by the main peak, attributed mostly to $\mathrm{Fe}^{3+}$ valence form is observed at the initial gas atmosphere and thermal conditions $\left(13 \mathrm{~Pa} \mathrm{O}_{2}\right.$ and $13 \mathrm{~Pa} \mathrm{H}_{2}$ at $423 \mathrm{~K}$ ). Upon further temperature increase such structure of $\mathrm{L}_{3}$ and $\mathrm{L}_{2}$-edge become changed. Then upon the firstly introduced hydrogen atmosphere a significant intensity drop of peaks along with their broadening and shifting toward lower energy, as well as the peak splitting is observed. At $673 \mathrm{~K}$ upon hydrogen exposure the structure of L-edges remains as a broad and low intensity peak at lower energy. Such behavior, similarly as in case of $\mathrm{O} \mathrm{K}$-edge, indicates the occurrence of the reduction of the metal oxide surface. The predominating valence form of iron is $\mathrm{Fe}^{2+}$, what is consistent with the observed XPS Fe2p core level. Then the introduction of the oxygen atmosphere at decreased temperature (13 Pa $\mathrm{O}_{2}, 423 \mathrm{~K}$ ) results in a restoration of the electronic structure to its initial state with the double peak splitting of L-edges and significant increase of the spectral intensity. This indicates that $\mathrm{Fe}^{3+}$ is a predominating valence form of iron. Therefore, the introduction of oxygen into the highly oxygen deficient surface of metal oxide seems to reverse the reduction effect. Upon further temperature increase under the oxygen atmosphere the double peak character of preedge region remains, however overall spectral intensity decreases. This decrease is resultant of the increasing number of $d$ electrons and related contribution of $\mathrm{Fe}^{2+}$.

In situ AP-NEXAFS results reveal that the electronic structure of these two phases of $\mathrm{Fe}_{2} \mathrm{O}_{3}$ nanoparticles strongly depends on the surrounding gas atmosphere and thermal conditions. $\gamma$ $\mathrm{Fe}_{2} \mathrm{O}_{3}$ is more susceptible to the reduction, however it undergoes as easily the re-oxidation as $\alpha-\mathrm{Fe}_{2} \mathrm{O}_{3}$. 

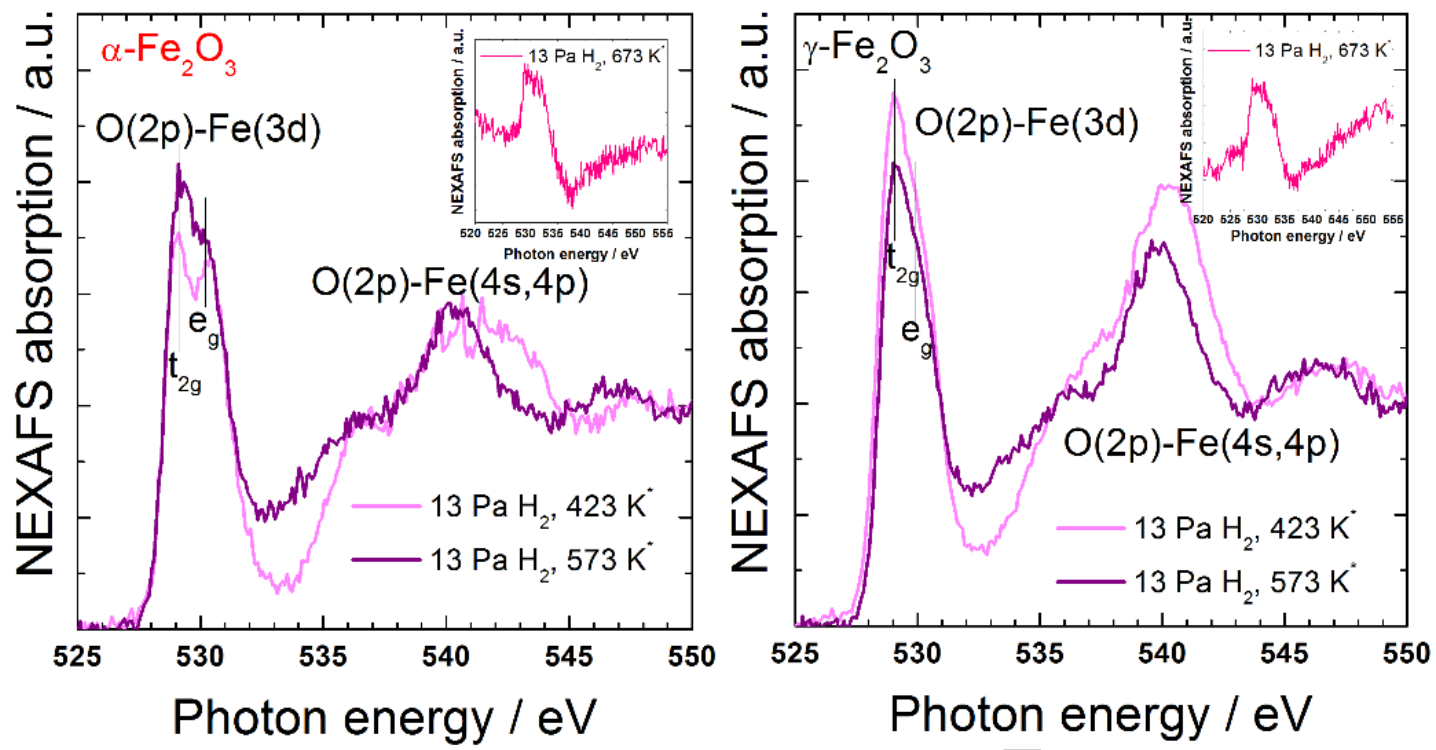

Fig. 6 Normalized $\mathrm{O}$ K-edge NEXAFS of $\alpha-\mathrm{Fe}_{2} \mathrm{O}_{3}$ (left) and $\gamma$ - $\mathrm{Fe}_{2} \mathrm{O}_{3}$ (right) under applied gas atmosphere and thermal conditions (see description insets in the figure).
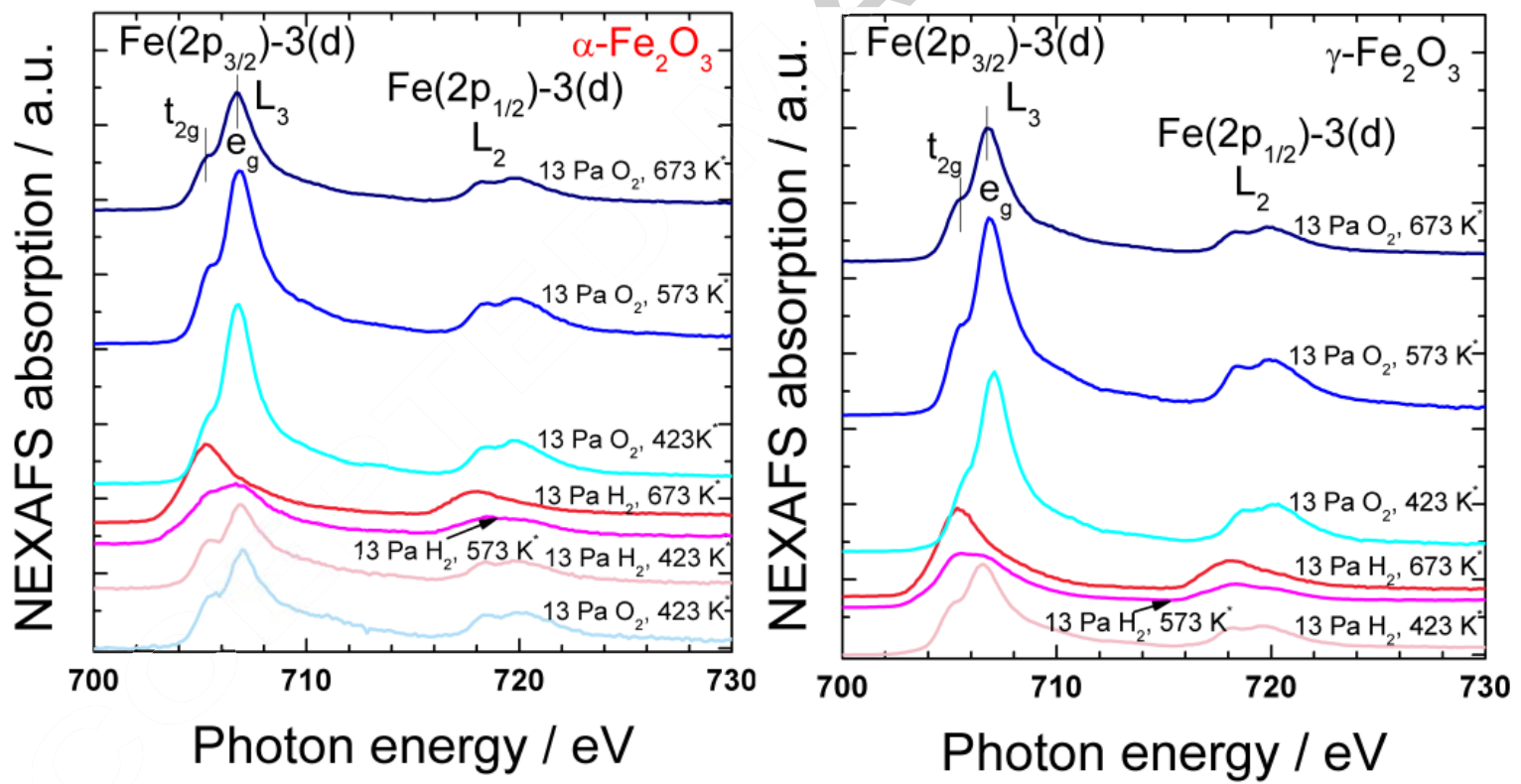

Fig. 7 Normalized Fe L-edge NEXAFS of $\alpha-\mathrm{Fe}_{2} \mathrm{O}_{3}$ (left) and $\gamma-\mathrm{Fe}_{2} \mathrm{O}_{3}$ (right) under applied gas atmosphere and thermal conditions (see description insets in the figure).

\subsection{Sensor response}

Observed resultant reversible electronic structure changes of $\gamma-\mathrm{Fe}_{2} \mathrm{O}_{3}$ and $\alpha-\mathrm{Fe}_{2} \mathrm{O}_{3}$ upon oxidizing and reducing gases exposure indicate that these nanoparticles can be exploited for gas sensing purposes. Therefore, the gas sensor response of $\gamma-\mathrm{Fe}_{2} \mathrm{O}_{3}$ and $\alpha-\mathrm{Fe}_{2} \mathrm{O}_{3}$ towards hydrogen, as a function of the gas concentration and operating temperature was investigated and is presented in Fig. 8. Two conductivity types can be resolved as $\mathrm{S}<1$ denotes n-type conductivity and $\mathrm{S}>1$ denotes p-type conductivity. $\gamma-\mathrm{Fe}_{2} \mathrm{O}_{3}$-based sensor shows n-type 
conductivity up to $573 \mathrm{~K}$, while $\alpha-\mathrm{Fe}_{2} \mathrm{O}_{3}$-based sensor p-type conductivity. This correlates with the XPS and NEXAFS results, where $\gamma-\mathrm{Fe}_{2} \mathrm{O}_{3}$ have been shown to offer more active sites for hydrogen gas molecules interaction, which results in surface oxygen deficiency, as well as presence of reduced Fe species. This is a cause of free electrons release into the conduction band and thus n-type conductivity behavior. At the temperature of $673 \mathrm{~K}$ the conductivity type of $\gamma$ - $\mathrm{Fe}_{2} \mathrm{O}_{3}$-based sensor changes from n-type to $\mathrm{p}$-type, what is also accompanied by the decrease of the sensor response. This can be related to the structure reordering with the contribution of the iron vacancies and associated electron holes. In both sensor cases the strongest sensor response is observed at operating temperature of $523 \mathrm{~K}$.

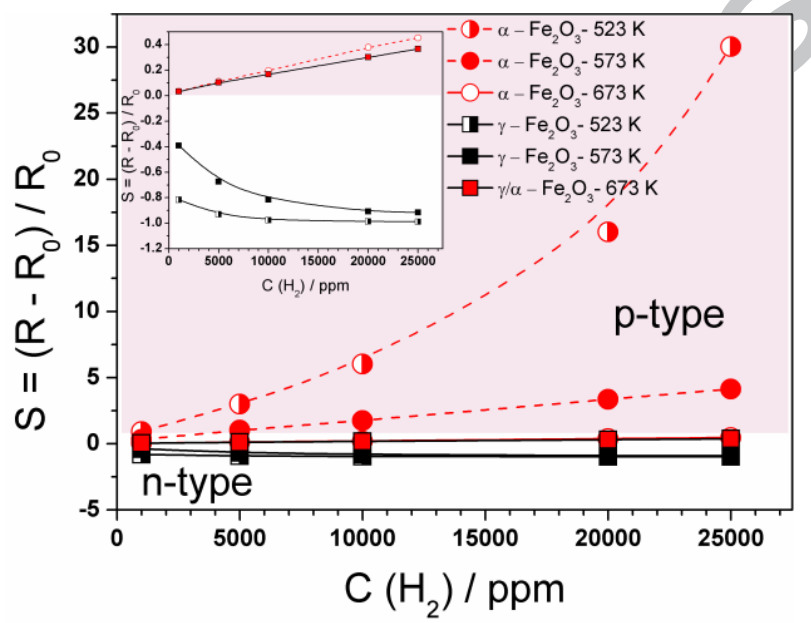

Fig. 8. Sensor characteristics of hydrogen detection with $\alpha-\mathrm{Fe}_{2} \mathrm{O}_{3}$ and $\gamma-\mathrm{Fe}_{2} \mathrm{O}_{3}$ nanoparticles-based sensor under different operating temperatures. Note: "“-" and "+" signs of sensor response correspond to the n-type and p-type conductivity, respectively.

\section{Conclusions}

The chemical interaction of surrounding gas molecules with the two polymorphic forms of $\mathrm{Fe}_{2} \mathrm{O}_{3}$ nanoparticles was investigated with the in situ ambient pressure XPS upon the oxygen and hydrogen exposure and applied temperature of 423 - $673 \mathrm{~K}$. Results indicate that the interaction of $\mathrm{Fe}_{2} \mathrm{O}_{3}$ surface with the oxidizing and reducing gas molecules can be considered as a catalytic reaction at the semiconductor surface (oxidation and reduction) giving a rise to distinct changes in the free electron concentration and resultant changes in the electrical behavior. The reactivity of these two polymorphs seems to have a similar character based on the contribution of oxygen vacancy defect states and related material non-stoichiometry. However, some differences can be still resolved such as: $\gamma-\mathrm{Fe}_{2} \mathrm{O}_{3}$ undergoes the reduction preferentially with a contribution of metallic $\mathrm{Fe}^{0}$ and exhibits more covalent character of $\gamma$ $\mathrm{Fe}_{2} \mathrm{O}_{3}$ than $\alpha-\mathrm{Fe}_{2} \mathrm{O}_{3}$. Observed reduction process is almost entirely reversible. Simultaneously, the electronic structure was monitored by the ambient pressure NEXAFS. Iron chemical state 
was found to be affected by switching the gas atmosphere from reducing to oxidizing and also upon changing the temperature. At the initial temperature of $423 \mathrm{~K}$ and upon oxygen exposure $\mathrm{Fe}^{3+}$ is the dominant form particularly for $\alpha-\mathrm{Fe}_{2} \mathrm{O}_{3}$, while $\gamma-\mathrm{Fe}_{2} \mathrm{O}_{3}$ exhibits a significant contribution of the reduced $\mathrm{Fe}^{2+}$ next to $\mathrm{Fe}^{3+}$. In turn, upon exposure towards hydrogen and increasing temperature the reduction of the oxide surface occurs (greater in case of $\gamma-\mathrm{Fe}_{2} \mathrm{O}_{3}$ ). However, upon the following oxygen exposure, a rapid re-oxidation process is observed already at low temperature of $423 \mathrm{~K}$. Prepared $\gamma-\mathrm{Fe}_{2} \mathrm{O}_{3}$ and $\alpha-\mathrm{Fe}_{2} \mathrm{O}_{3}$ nanostructures exhibit high n-type and p-type sensor response towards hydrogen, respectively, in a wide concentrations range, therefore have the potential as sensing materials.

\section{Acknowledgements}

During the experiments and the preparation of this manuscript, A.B and B.S.M were supported by the Korean-Swiss Science and Technology Programme (KSSTP) Project (NRF NRF-2015K1A3A1A14021261 and SNF IZKSZ2-162232), and a project from the Second Call. Q.C. received financial support by SNF 200021-124812. D.F. would like to thank to Dr. Grzegorz Nowaczyk for the TEM analysis. The Advanced Light Source is supported by the Director, Office of Science, Office of Basic Energy Sciences, of the U.S. Department of Energy under Contract No. DE-AC02-05CH11231.

\section{Literature}

[1] K.-D. Schierbaum, Engineering of oxide surfaces and metal/oxide interfaces for chemical sensors: recent trends, Sens. Actuators, B 24 (1995) 239-247.

[2] V.E. Henrich, P.A. Cox, The Surface Science of Metal Oxides, University Press, Cambridge, 1994.

[3] G. Heiland, Homogeneous semiconducting gas sensors, Sens. Actuators, 2 (1981) 343361.

[4] S.R. Morrison, Mechanism of semiconductor gas sensor operation, Sens. Actuators 11 (1987) 283-287.

[5] Drake C., Seal S., Band gap energy modifications observed in trivalent in substituted nanocrystalline $\mathrm{SnO}_{2}$, Appl. Phys. Lett. 90 (2007) 233117.

[6] E.L. Miller, D. Paluselli, B. Marsen, R.E. Rocheleau, Low-temperature reactively sputtered iron oxide for thin film devices, Thin Solid Films 466 (2004) 307-313. 
[7] J.Y. Kim, G. Magesh, D.H. Youn, J.-W. Jang, J. Kubota, K. Domen, J.S. Lee, Singlecrystalline, wormlike hematite photoanodes for efficient solar water splitting, Sci. Rep. 3 (2013) 2681.

[8] J.Y.T. Chan, S.Y. Ang, E.Y. Ye, M. Sullivan, J. Zhang, M. Lin, Heterogeneous photoFenton reaction on hematite $\left(\alpha-\mathrm{Fe}_{2} \mathrm{O}_{3}\right)\{104\},\{113\}$ and $\{001\}$ surface facets, Phys. Chem. Chem. Phys. 17 (2015) 25333-25341.

[9] N. Tian, J. Yu, Y. Deng, G. Li, X. Zhang, Electrical properties of $\mathrm{Ce}_{0.85} \mathrm{Sm}_{0.15} \mathrm{O}_{1.925}-\mathrm{Fe}_{2} \mathrm{O}_{3}$ electrolytes for IT-SOFCs, J. Alloys Compd. 655 (2016) 215-219.

[10] D. Flak, A. Braun, A. Vollmer, M. Rekas, Effect of the titania substitution on the electronic structure and transport properties of FSS-made $\mathrm{Fe}_{2} \mathrm{O}_{3}$ nanoparticles for hydrogen sensing, Sens. Actuators, B 187 (2013) 347-355.

[11] A. Braun, F.E. Huggins, K.E. Kelly, B.S. Mun, S.N. Ehrlich, G.P. Huffman, Impact of ferrocene on the structure of diesel exhaust soot as probed with wide-angle X-ray scattering and C(1s) NEXAFS spectroscopy, Carbon 44 (2006) 2904-2911.

[12] L.A. Patil, M.D. Shinde, A.R. Bari, V.V. Deo, D.M. Patil, M.P. Kaushik, $\mathrm{Fe}_{2} \mathrm{O}_{3}$ modified thick films of nanostructured $\mathrm{SnO}_{2}$ powder consisting of hollow microspheres synthesized from pyrolysis of ultrasonically atomized aerosol for LPG sensing, Sens. Actuators, B 155 (2011) 174-182.

[13] M. Rumyantseva, V. Kovalenko, A. Gaskov, E. Makshina, V. Yuschenko, I. Ivanova, A. Ponzoni, G. Faglia, E. Comini, Nanocomposites $\mathrm{SnO}_{2} / \mathrm{Fe}_{2} \mathrm{O}_{3}$ : Sensor and catalytic properties, Sens. Actuators, B 118 (2006) 208-214.

[14] O.K. Tan, W. Cao, Y. Hu, W. Zhu, Nanostructured oxides by high-energy ball milling technique: application as gas sensing materials, Solid State Ionics 172 (2004) 309-316.

[15] M. Zhang, W. Luo, Z. Li, T. Yu, Z. Zou, Improved photoelectyrochemical responses of Si and Ti codoped a- $\mathrm{Fe}_{2} \mathrm{O}_{3}$ photoanopde, Appl. Phys. Lett. 97 (2010) 0421051-0421053.

[16] Gurlo A., Sahm M., Oprea A., Barsan N., Weimar U., A p- to n-transition on a- $\mathrm{Fe}_{2} \mathrm{O}_{3}-$ based thick film sensors studied by conductance and work function change measurements, Sens. Actuators, B 102 (2004) 291-298.

[17] M. Salmeron, Ambient pressure photoelectron spectroscopy: a new tool for surface science and nanotechnology, Surf. Sci. Rep. 63 (2008) 169-199. 
[18] D.E. Starr, Z. Liu, M. Havecker, A. Knop-Gericke, H. Bluhm, Investigation of solid/vapor interfaces using ambient pressure X-ray photoelectron spectroscopy, Chem. Soc. Rev. 42 (2013) 5833-5857.

[19] G. Rupprechter, C. Weilach, Spectroscopic studies of surface-gas interactions and catalyst restructuring at ambient pressure: mind the gap!, J. Phys.: Condens. Matter 20 (2008) 184019.

[20] F. Gao, S.M. McClure, Y. Cai, K.K. Gath, Y. Wang, M.S. Chen, Q.L. Guo, D.W. Goodman, CO oxidation trends on Pt-group metals from ultrahigh vacuum to near atmospheric pressures: A combined in situ PM-IRAS and reaction kinetics study, Surf. Sci. 603 (2009) 65-70.

[21] J.-J. Velasco-Velez, C.H. Wu, T.A. Pascal, L.F. Wan, J. Guo, D. Prendergast, M. Salmeron, The structure of interfacial water on gold electrodes studied by X-ray absorption spectroscopy, Science 346 (2014) 831-834.

[22] D. Flak, A. Braun, K.A. Michalow, J. Wyrwa, M. Parlinska-Wojtan, T. Graule, M. Rekas, Differences in Electrophysical and Gas Sensing Properties of Flame Spray Synthesized $\mathrm{Fe}_{2} \mathrm{O}_{3}\left(\alpha-\mathrm{Fe}_{2} \mathrm{O}_{3}\right.$ and $\left.\gamma-\mathrm{Fe}_{2} \mathrm{O}_{3}\right)$, J. Nanosci. Nanotechnol. 12 (2012) 6401-6411.

[23] D. Flak, A. Braun, B.S. Mun, J.B. Park, M. Parlinska-Wojtan, T. Graule, M. Rekas, Spectroscopic assessment of the role of hydrogen in surface defects, in the electronic structure and transport properties of $\mathrm{TiO}_{2}, \mathrm{ZnO}$ and $\mathrm{SnO}_{2}$ nanoparticles, Phys. Chem. Chem. Phys. (2012).

[24] J.A. Whaley, A.H. McDaniel, F. El Gabaly, R.L. Farrow, M.E. Grass, Z. Hussain, Z. Liu, M.A. Linne, H. Bluhm, K.F. McCarty, Note: Fixture for characterizing electrochemical devices in-operando in traditional vacuum systems, Rev. Sci. Instrum. 81 (2010) 086104.

[25] C. Zhang, M.E. Grass, A.H. McDaniel, S.C. DeCaluwe, F. El Gabaly, Z. Liu, K.F. McCarty, R.L. Farrow, M.A. Linne, Z. Hussain, G.S. Jackson, H. Bluhm, B.W. Eichhorn, Measuring fundamental properties in operating solid oxide electrochemical cells by using in situ X-ray photoelectron spectroscopy, Nat. Mater. 9 (2010) 944-949

[26] M.E. Grass, P.G. Karlsson, F. Aksoy, M. Lundqvist, B. Wannberg, B.S. Mun, Z. Hussain, Z. Liu, New ambient pressure photoemission endstation at Advanced Light Source beamline 9.3.2, Rev. Sci. Instrum. 81 (2010) 053106. 
[27] Z. Hussain, W.R.A. Huff, S.A. Kellar, E.J. Moler, P.A. Heimann, W. McKinney, H.A. Padmore, C.S. Fadley, D.A. Shirley, High resolution soft X-ray bending magnet beamline 9.3.2 with circularly polarized radiation capability at the Advanced Light Source, J. Electron Spectrosc. Relat. Phenom. 80 (1996) 401-404.

[28] D.F. Ogletree, B. Hendrik, L. Gennadi, S.F. Charles, H. Zahid, S. Miquel, A differentially pumped electrostatic lens system for photoemission studies in the millibar range, Rev. Sci. Instrum. 73 (2002) 3872-3877.

[29] Majylan., Navrotsky A., Schwertmann U., Thermodznamics of iron oxides: Part III. Entalpies of formation and stability of ferrihydrite $\left(\mathrm{Fe}(\mathrm{OH})_{3}\right)$, schwertmannite $\left(\mathrm{FeO}(\mathrm{OH})_{3 / 4}\left(\mathrm{SO}_{4}\right)_{1 / 8}\right)$, and e- $\mathrm{Fe}_{2} \mathrm{O}_{3}$, Geochim. Cosmochim. Acta 68 (2004) 1049-1059.

[30] C. Laberty, A. Navrotsky, Energetics of stable and metastable low-temperature iron oxides and oxyhydroxides, Geochim. Cosmochim. Acta 62 (1998) 2905-2913.

[31] X. Deng, J. Lee, C. Wang, C. Matranga., F. Aksoy, Z. Liu, Reactivity Differences of Nanocrystals and Continuous Films of $\mathrm{a}-\mathrm{Fe}_{2} \mathrm{O}_{3}$ on $\mathrm{Au}(111)$ Studied with In Situ X-ray Photoelectron Spectroscopy, J. Phys. Chem. C 114 (2010) 22619-22623.

[32] J.-C. Dupin, D. Gonbeau, P. Vinatier, A. Levasseur, Systematic XPS studies of metal oxides, hydroxides and peroxides, Phys. Chem. Chem. Phys. 2 (2000) 1319-1324.

[33] J.L. Junta-Rosso, J.M.F. Hochella, The chemistry of hematite 001 surfaces, Geochim. Cosmochim. Acta, 60 (1996) 305-314.

[34] S. Yamamoto, T. Kendelewicz, J.T. Newberg, G. Ketteler, D.E. Starr, E.R. Mysak, K.J. Andersson, H. Ogasawara, H. Bluhm, M. Salmeron, J. Brown, G.E., Nilsson A., Water Adsorption on a-Fe $\mathrm{O}_{3}(0001)$ at near Ambient Conditions, J. Phys. Chem. C 114 (2010) $2256-2266$.

[35] Q. Chen, F. El Gabaly, F. Aksoy Akgul, Z. Liu, B.S. Mun, S. Yamaguchi, A. Braun, Observation of Oxygen Vacancy Filling under Water Vapor in Ceramic Proton Conductors in Situ with Ambient Pressure XPS, Chem. Mat. 25 (2013) 4690-4696.

[36] T. Fujii, F.M.F. de Groot, G.A. Sawatzky, F.C. Voogt, T. Hibma, K. Okada, In situ XPS analysis of various iron oxide films grown by $\mathrm{NO}_{2}$-assisted molecular-beam epitaxy, Phys. Rev. B 59 (1999) 3195-3202.

[37] Fujimori A., Saeki M., Kimizuka N., Photoemission satellites and electronic structure of $\mathrm{Fe}_{2} \mathrm{O}_{3}$, Phys. Rev. B, 34 (1986) 7318-7328. 
[38] P.C.J. Graat, M.A.J. Somers, Simultaneous determination of composition and thickness of thin iron-oxide films from XPS Fe 2p spectra, Appl. Surf. Sci. 100-101 (1996) 36-40.

[39] E. de Smit, M.M. van Schooneveld, F. Cinquini, H. Bluhm, P. Sautet, F.M.F. de Groot, B.M. Weckhuysen, On the Surface Chemistry of Iron Oxides in Reactive Gas Atmospheres, Angew. Chem.-Int. Edit. 50 (2011) 1584-1588.

[40] D.K. Bora, A. Braun, S. Erat, O. Safonova, T. Graule, E.C. Constable, Evolution of structural properties of iron oxide nano particles during temperature treatment from 250$900^{\circ} \mathrm{C}$ : X-ray diffraction and Fe K-shell pre-edge X-ray absorption study, Curr. Appl.Phys. 12 (2012) 817-825.

[41] I.D. Welsh, P.M.A. Sherwood, Photoemission and electronic structure of FeOOH: Distinguishing between oxide and oxyhydroxide, Phys. Rev. B 40 (1989) 6386-6392.

[42] W. Temesghen, P.M.A. Sherwood, Analytical utility of valence band X-ray photoelectron spectroscopy of iron and its oxides, with spectral interpretation by cluster and band structure calculations, Anal. Bioanal. Chem. 373 (2002) 601-608.

[43] N.S. McIntyre, D.G. Zetaruk, X-ray photoelectron spectroscopic studies of iron oxides, Anal. Chem. 49 (1977) 1521-1529.

[44] J.G. Chen, B. Fruhberger, M.L. Colaianni, Near-edge x-ray absorption fine structure characterization of compositions and reactivities of transition metal oxides, J. Vac. Sci. Technol. A 14 (1996) 1668-1673.

[45] F.M.F. de Groot, M. Grioni, J.C. Fuggle, J. Ghijsen, G.A. Sawatzky, H. Petersen, Oxygen 1s X-ray-absorption edges of transition-metal oxides, Phys. Rev. B 40 (1989) 57155723.

[46] K. Gajda-Schrantz, S. Tymen, F. Boudoire, R. Toth, D.K. Bora, W. Calvet, M. Gratzel, E.C. Constable, A. Braun, Formation of an electron hole doped film in the $\mathrm{a}-\mathrm{Fe}_{2} \mathrm{O}_{3}$ photoanode upon electrochemical oxidation, Phys. Chem. Chem. Phys. 15 (2013) 1443-1451. 
Highlights:

- Chemical reactivity investigation of $\mathrm{Fe}_{2} \mathrm{O}_{3}$ polymorph NPs by in situ XPS and NEXAFS

- Reactivity of $\mathrm{Fe}_{2} \mathrm{O}_{3}$ polymorph NPs is based on the material non-stoichiometry

- $\gamma-\mathrm{Fe}_{2} \mathrm{O}_{3}$ more covalent than $\alpha-\mathrm{Fe}_{2} \mathrm{O}_{3}$ in particular upon interaction with $\mathrm{H}_{2}$

- $\gamma-\mathrm{Fe}_{2} \mathrm{O}_{3}$ undergoes reduction preferentially with contribution of $\mathrm{Fe}^{0}$ unlike $\alpha-\mathrm{Fe}_{2} \mathrm{O}_{3}$

- Electronic structure changes of $\mathrm{Fe}_{2} \mathrm{O}_{3}$ NPs upon $\mathrm{O}_{2}$ and $\mathrm{H}_{2}$ exposures are reversible 
Graphical abstract

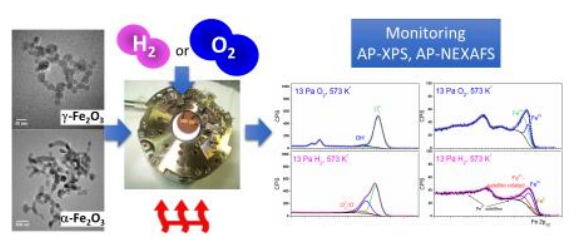

